EXPERIMENTAL STUDY

\title{
Prolonged low-dose infusion of human parathyroid hormone does not increase femoral cancellous bone volume in ovariectomized rats
}

\author{
P Morley, J F Whitfield, G E Willick, V Ross, S MacLean, R J Isaacs, E Mendoza and J-R Barbier \\ Institute for Biological Sciences, National Research Council of Canada, Building M-54, Montreal Road Campus, Ottawa, Ontario, Canada K1A OR6 \\ (Correspondence should be addressed to P Morley)
}

\begin{abstract}
Objective: Daily injections of human parathyroid hormone (hPTH) increase bone volume in various animal species and in osteoporotic women. For hPTH to be widely accepted as an anabolic therapy for treating postmenopausal osteoporosis alternative delivery options need to be explored to replace the need for daily patient subcutaneous self-injection. Among these are inhalation, oral delivery and the use of programmable implanted minipumps to deliver the peptide. While infusion of high doses of PTH causes bone loss and hypercalcemia, no studies have assessed the effects of prolonged infusion of low doses of PTH on bone growth.

Design and Methods: [Leu $\left.{ }^{27}\right]$-cyclo(Glu ${ }^{22}$-Lys $\left.{ }^{26}\right)$-hPTH-(1-31) $\mathrm{NH}_{2}$ was delivered by Alzet minipumps to ovariectomized rats for 6 weeks after which histomorphometric indices (cancellous bone volume, trabecular thickness, mean trabecular number) of bone formation were measured in distal femurs. Results: Infusing low doses (0.05 and 0.1 nmole/ $100 \mathrm{~g}$ body weight/day) of the hPTH analog, $\left[\mathrm{Leu}^{27}\right]$-cyclo(Glu ${ }^{22}$-Lys $\left.{ }^{26}\right)$-hPTH-(1-31) $\mathrm{NH}_{2}$, for 6 weeks does not prevent the ovariectomy-induced loss of rat femoral cancellous bone volume, trabecular thickness or trabecular number.

Conclusion: These results support the absolute requirement of daily injections for the osteogenic action of hPTH on bone.
\end{abstract}

European Journal of Endocrinology $\mathbf{1 4 1} 70-74$

\section{Introduction}

Daily injections of small doses of parathyroid hormone (PTH) which cause brief plasma pulses of the hormone stimulate bone growth in various species and, most importantly, in osteoporotic women (1-5). Recently, an elegant series of studies addressed the question of the optimal duration of plasma PTH pulses for anabolic effects on bone (6). While PTH administered in oncedaily subcutaneous injections or infusions for $1 \mathrm{~h} /$ day dramatically increased osteoblast numbers and bone formation in ovariectomized rats, longer infusions $(80 \mu \mathrm{g} / \mathrm{kg} /$ day for 6 days $)$ resulted in a loss of body weight, hypercalcemia and resorption of cancellous and cortical bone (7-10). In the clinic, the need for daily subcutaneous injections could negatively affect patient compliance over the 1-2 years required to restore bone mineral density above the fracture threshold. Alternative delivery systems for the intrapulmonary, intranasal or oral delivery of PTH are in the early stages of clinical development.

Low-dose PTH infusions in male rats increase both bone formation and resorption (9) and in dogs, osteo-clastic surfaces were clearly increased by low-dose PTH infusion (11). This suggests that the duration of PTH exposure must be very short for the hormone to be anabolic. But we do not know whether prolonged infusion of low doses of PTH that do not cause hypercalcemia can be anabolic. If they are, implanted infusion pumps would be ideal for delivering hPTH to osteoporotic patients. However, here we show that 6-week infusions of low doses (0.05, 0.1 and 0.5 nmole/ $100 \mathrm{~g}$ body weight (BW)/day) of the potent new human (h) PTH analog, [ $\left[\mathrm{Leu}^{27}\right]$-cyclo $\left(\mathrm{Glu}^{22}\right.$-Lys $\left.{ }^{26}\right)$-hPTH$(1-31) \mathrm{NH}_{2}(12,13)$, do not prevent loss of cancellous bone volume in the distal femurs of ovariectomized (OVXed) rats.

\section{Materials and methods}

\section{PTH fragment and infusions}

$\left[\mathrm{Leu}^{27}\right]$-cyclo(Glu $\left.{ }^{22}-\mathrm{Lys}^{26}\right)$-hPTH-(1-31) $\mathrm{NH}_{2}$ was made in this Institute using the same Fmoc protocol and continuous-flow peptide synthesizer (PerSeptive Biosystems 
Model 9050, Framingham, MA, USA) described earlier $(12,14,15)$. The peptide was dissolved in an acidic saline vehicle $(0.15 \mathrm{~mol} / \mathrm{l} \mathrm{NaCl}$ in water containing $0.001 \mathrm{M} \mathrm{HCl})$.

The analog was infused in Alzet Model 2002 minipumps (Alza Corporation, Palo Alto, CA, USA) at doses of 0.05, 0.1 and $0.5 \mathrm{nmole} / 100 \mathrm{~g}$ BW/day. These doses are the equivalent of administering $0.72,1.48$ and $7.36 \mu \mathrm{g}\left[\mathrm{Leu}^{27}\right]$-cyclo $\left(\mathrm{Glu}^{22}\right.$-Lys $\left.{ }^{26}\right)$-hPTH-(1$31) \mathrm{NH}_{2} /$ rat/day. The pumps were implanted subcutaneously in a pocket under the skin on the back of the rat. This model pumps $0.5 \mu \mathrm{l} / \mathrm{h}$ for 14 days; thus the pumps were replaced on days 14 and 28 .

\section{Assay of osteogenic effects of PTH on bone}

In this study we used sexually mature, OVXed 3-monthold rats. This model is widely used because it combines the easy manageability of rats with the main features of postmenopausal osteoporosis in women such as rapid and selective loss of cancellous bone and skeletal responsiveness to bisphosphonates and PTH fragments $(5,14,16)$. It is also one of the two animal models required by the United States Food and Drug Administration for the preclinical assessment of drugs for treating osteoporosis (17).

Sham-OVXed and OVXed female Sprague-Dawley rats were bought from Charles River Breeding Laboratories (St Constant, QC, Canada). Upon arrival, they were randomly distributed into five groups (sham-OVXed, vehicle-treated OVXed and 3 infusion groups of [Leu $\left.{ }^{27}\right]$ cyclo $\left(\mathrm{Glu}^{22}\right.$-Lys $\left.{ }^{26}\right)$-hPTH-(1-31) $\mathrm{NH}_{2}$-treated OVXed rats) of 5-8 animals each. Purina rat chow $(1.0 \%$ calcium, $0.6 \%$ phosphorus) and water were available ad libitum. These experiments were approved by this Institute's Animal Care Committee.

The experiment was a restorative experiment designed to compare the abilities of the fragments to increase the volume of the cancellous bone remaining in the severely depleted cancellous bone of rats several weeks after ovariectomy (OVX). In this experiment, the hPTH infusions were started at the end of the 9th week after OVX and continued until the end of the 15 th week after OVX (i.e. the end of the 6th week after the infusion began). The sham-OVXed control rats were untreated and the OVXed control rats received vehicle infusions.

Although hPTH fragments can stimulate cortical bone growth in still-growing young rats such as those used in these experiments $(14,18)$, we focused on distal femoral cancellous bone because its responses to OVX and PTH fragments are proportionally much larger and therefore more easily and accurately measured $(13,14$, 16, 19). Femurs were removed from euthanized rats and cleaned. Each bone was then cut in half at middiaphysis and the proximal half was discarded. After removing the epiphysis, each half-femur was split lengthwise into two parts and the marrow was flushed out with distilled water from a dental 'water pik'. The de-marrowed half-femurs were fixed in acetate-buffered $10 \%$ formalin for at least $24 \mathrm{~h}$, demineralized by being stirred in 5\% trichloroacetic acid at room temperature for about 2 weeks, and then dehydrated, cleared, and embedded in paraffin. Serial, $10-\mu \mathrm{m}$ sections were cut with a Leica RM-2035 microtome and stained for $30 \mathrm{~s}$ with Sanderson's rapid bone stain (Surgipath Medical Industries Inc., Winnipeg MB, Canada).

The osteogenic potency of the infused hPTH analog was indicated by how much it had increased the metaphyseal cancellous bone volume $\left(\mathrm{mm}^{3}\right)$ and the mean thickness (area $\left[\mu \mathrm{m}^{2}\right] \div$ perimeter $\left.[\mu \mathrm{m}]\right)$ of 80-100 individual trabeculae in each bone section (and a total of 400-640 trabeculae for each experimental group). To calculate the cancellous bone volume in a $100-\mu \mathrm{m}$-thick slice of distal femur, the sums of the longitudinal trabecular areas in the entire metaphyses in 10 serial $10-\mu \mathrm{m}$ sections were added to obtain the cancellous bone volume. The cancellous bone areas and perimeters were measured with an M4 imaging system from Imaging Research Inc. (St Catherine's, ON, Canada). The computer software used was Imaging Research's morphometric version 1.2. All of the measurements were made by the same person, who was blind to the treatment groups, to minimize variation from the unavoidably subjective component of such an analysis.

The effects of OVX and infusion of the hPTH analog on the number of trabeculae in the distal femurs were also compared. We did not count the actual total number of trabeculae in each section. Instead we counted the number of trabecular contacts or 'hits' made by 15 lines drawn across the bone sections perpendicular to the sections' long axes from the condyles into the diaphysis, which would have been directly proportional to the total numbers of trabeculae in the sections. To determine these trabecular 'hit' frequencies, the 15 lines were drawn at $0.5 \mathrm{~mm}$ intervals across each one of the 5 sections of a distal femur starting at a point in the diaphysis $5 \mathrm{~mm}$ from the intercondylar notch and extending forward for $7.5 \mathrm{~mm}$ from the starting point into the condyles. The trabecular 'hits'/mm made by the 15 lines on each of the 5 sections of each of the 5 to 8 distal femurs from the rats of an experimental group were pooled to give a total number of 375 to 600 estimates for calculating the overall mean trabecular 'hit' frequency for the bones of that group.

\section{Blood calcium measurements}

Blood calcium concentrations were measured using the $O$-cresolphthalien complexone procedure (Ciba Corning Diagnostics Corp., Oberlin, OH, USA).

\section{Statistical analysis}

All data were expressed as means \pm s.E.M. Statistical comparisons were made by one-way analysis of variance 
Table 1 Effect of $\left[\mathrm{Leu}^{27}\right]$-cyclo(Glu $\left.{ }^{22}-\mathrm{Lys}^{26}\right)$-hPTH-(1-31) $\mathrm{NH}_{2}$ continuously infused at 0.1 and $0.05 \mathrm{nmole} / 100 \mathrm{~g} \mathrm{BW} /$ day on cancellous bone volume, trabecular thickness and mean trabecular number in distal femurs following OVX. The data are the means \pm S.E.M. of the cancellous bone volumes in the distal femurs from 5-8 rats, the pooled thicknesses of 400-480 trabeculae in the distal femurs of each treatment group, and the mean \pm S.E.M. of the 15 trabecular 'hit' frequencies from all of the 5 sections from each of the 5 bones in each treatment group. (i.e. about 375 determinations).

\begin{tabular}{lccc}
\hline & $\begin{array}{c}\text { Cancellous bone } \\
\text { volume }\left(\mathrm{mm}^{3}\right)\end{array}$ & $\begin{array}{c}\text { Trabecular } \\
\text { thickness }(\mu \mathrm{m})\end{array}$ & $\begin{array}{c}\text { Mean trabecular } \\
\text { number ('hits'/mm) }\end{array}$ \\
\hline Sham & $1.25 \pm 0.16^{\mathrm{a}}$ & $41.6 \pm 3.0^{\mathrm{a}}$ & $5.2 \pm 0.15^{\mathrm{a}}$ \\
OVX & $0.40 \pm 0.08^{\mathrm{b}}$ & $33.1 \pm 1.0^{\mathrm{a}}$ & $1.7 \pm 0.08^{\mathrm{b}}$ \\
0.1 nmole/100 g BW/day & $0.27 \pm 0.02^{\mathrm{b}}$ & $33.1 \pm 1.2^{\mathrm{a}}$ & $1.2 \pm 0.07^{\mathrm{b}}$ \\
$0.05 \mathrm{nmole} / 100 \mathrm{~g} \mathrm{BW/day}$ & $0.20 \pm 0.02^{\mathrm{b}}$ & $30.9 \pm 0.7^{\mathrm{b}}$ & $1.3 \pm 0.06^{\mathrm{b}}$ \\
\hline
\end{tabular}

The infusions were started at the end of the 9th week after OVX and continued until the end of the 15th week after OVX. Values with different superscripts are significantly different $(P<0.05)$.

(ANOVA). When significant effects were observed Scheffe's test was used for multiple comparisons and $P<0.05$ was considered to be significant.

\section{Results}

In this experiment rats were OVXed and then infused with vehicle or $0.05,0.1$ or $0.5 \mathrm{nmole} / 100 \mathrm{~g} \mathrm{BW} /$ day (equivalent to $0.72,1.48$ and $7.36 \mu \mathrm{g} /$ day respectively) $\left[\mathrm{Leu}^{27}\right]$-cyclo $\left(\mathrm{Glu}^{22}\right.$-Lys $\left.{ }^{26}\right)$-hPTH- $(1-31) \mathrm{NH}_{2}$ for 6 weeks starting at the end of the 9th week after ovariectomy when at least $75 \%$ of the total femoral cancellous bone mass had been lost (18). The high dose, $0.5 \mathrm{nmole} / 100 \mathrm{~g} \mathrm{BW} /$ day, is within the osteogenic range when given in once-daily boluses $(13,16)$. Blood calcium concentrations were measured every 2 weeks to determine whether the hPTH analog infusions were causing bone resorption and hence hypercalcemia. On day 0 , the day before the implantation of the minipumps, the mean blood calcium concentration was $7.54 \pm 0.12 \mathrm{mg} \%$. The sham, OVX, 0.05 and $0.1 \mathrm{nmole} /$ $100 \mathrm{~g}$ BW/day groups had blood calcium concentrations within the normal range $(6.79 \pm 0.15$ to $7.56 \pm 0.09 \mathrm{mg} \%)$ throughout the experiment. However, the rats infused with the $0.5 \mathrm{nmole} / 100 \mathrm{~g} \mathrm{BW} /$ day group had elevated blood calcium concentrations $(10.69 \pm 0.50 \mathrm{mg} \%)$ after 4 weeks. This PTH dose was clearly too high and these rats were subsequently killed. The lower dose of $0.1 \mathrm{nmole} / 100 \mathrm{~g} \mathrm{BW/day} \mathrm{therefore} \mathrm{is,}$ or is close to, the upper limit at which PTH can be infused without significantly inducing bone resorption.

As expected, the cancellous bone volume $\left(0.40 \pm 0.08 \mathrm{~mm}^{3}\right)$ in the distal femurs of the OVXed rats at the end of the 15 th week after the operation was significantly lower $(P<0.05)$ than in the femurs of the sham-OVXed control rats $\left(1.25 \pm 0.16 \mathrm{~mm}^{3}\right)$ (Table 1$)$. The mean trabecular thickness in the femurs of the OVXed rats $(33.1 \pm 1.0 \mu \mathrm{m})$ by the end of the 15 th week after the operation was not significantly $(P>0.05)$ less than the mean trabecular thickness $(41.6 \pm 3.0 \mu \mathrm{m})$ in the sham-operated rats by the end of the 15 th week after the sham operation (Table 1). The overall mean trabecular 'hit' frequencies at the end of 15 weeks in the distal femurs from OVXed rats was $1.7 \pm 0.08$ compared with $5.2 \pm 0.15$ in the distal femurs from the shamoperated control rats (Table 1 ).

The cancellous bone volume and thickness of rat femurs following infusion of 0.1 or $0.05 \mathrm{nmole} / 100 \mathrm{~g}$ $\mathrm{BW} /$ day $\left[\mathrm{Leu}^{27}\right]$-cyclo $\left(\mathrm{Glu}^{22}\right.$-Lys $\left.^{26}\right)$-hPTH- $(1-31) \mathrm{NH}_{2}$ between the end of the 9th week and the end of the 15 th week after OVX were not significantly different $(P>0.05)$ from untreated OVX rats (Table 1$)$. The overall mean trabecular 'hit' frequency by the end of the 15 th week after OVX and 6 weeks of 0.1 or 0.05 nmole $/ 100 \mathrm{~g}$ BW/day $\left[\mathrm{Leu}^{27}\right]$-cyclo(Glu $\left.{ }^{22}-\mathrm{Lys}^{26}\right)$-hPTH- $(1-31) \mathrm{NH}_{2}$ infusion were respectively $1.2 \pm 0.07$ and $1.3 \pm 0.08$, which were not significantly different $(P>0.05)$ from the $1.7 \pm 0.08$ in the untreated OVXed rats (Table 1 ). The inability of continuous infusions of 0.1 and 0.05 nmole/

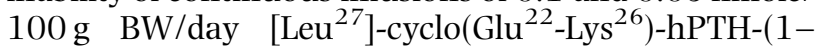
$31) \mathrm{NH}_{2}$ to increase cancellous bone volume in the restorative experiment of Table 1 can be seen in the typical specimens of demineralized distal femurs in Fig. 1.

\section{Discussion}

Daily treatment with PTH can both prevent OVXinduced bone loss and completely restore lost bone mass (but not trabecular number) in established osteopenia (1-5). At present, the major drawback of PTH therapy is that the hormone, or its analogs, must be injected subcutaneously, which might make it difficult to get good patient compliance over a period of several months. In addition to oral and nasal delivery, the pulmonary epithelium may be a good site for the noninjectable delivery of small peptides such as hPTH into the circulation (20).

In contrast to the anabolic actions of daily injections of PTH, continuous infusions of the hormone can strongly stimulate bone resorption with a resulting dramatic loss of cancellous and cortical bone and severe hypercalcemia $(6-10,21)$. Infusing hPTH(1-34) for 4 


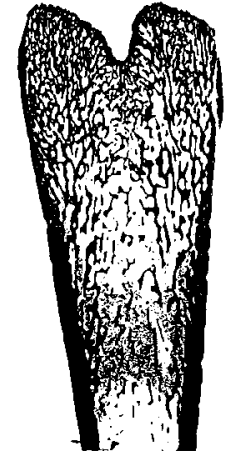

Sham

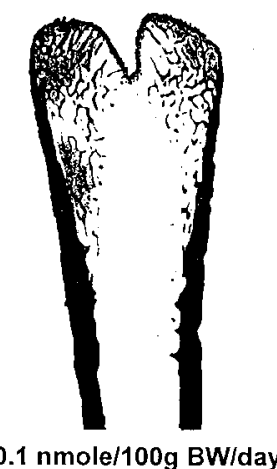

$0.1 \mathrm{nmole} / 100 \mathrm{~g}$ BW/day

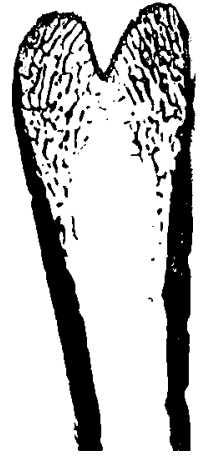

ovX

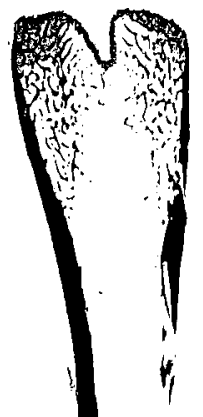

$0.05 \mathrm{nmole} / 100 \mathrm{~g}$ BW/day
Figure 1 Typical specimens of demineralized distal femurs showing the lack of effect of $\left[\mathrm{Leu}^{27}\right]$-cyclo $\left(\mathrm{Glu}^{22}-\mathrm{Lys}^{26}\right)$-hPTH-(1-31) $\mathrm{NH}_{2}$ continuously infused at 0.1 and $0.05 \mathrm{nmole} / 100 \mathrm{~g} \mathrm{BW} /$ day to increase cancellous bone volume in the experiment shown in Table 1.

weeks at $214 \mathrm{ng} / \mathrm{kg} / \mathrm{h}$ caused hypercalcemia, a decrease in femur dry weight, abnormal bone morphology and an increased porosity of the diaphyseal cortical bone of the tibia in rats (9). Histomorphometric analysis has also shown that low-dose hPTH infusions similarly increase both bone formation and resorption in male rats receiving $15 \mathrm{nmole} / \mathrm{kg} /$ day $\mathrm{hPTH}(1-34)$ for 6 days (8) or $0.4-102.4 \mathrm{MRC}$ units bPTH(1-84)/rat/day for 12 days (7). Treating young male rats with $0.25-8 \mu \mathrm{g} /$ $100 \mathrm{~g} \mathrm{BW} /$ day for 12 days (10), or dogs with $0.5 \mu \mathrm{g} / \mathrm{kg} /$ day for 6 months (11), failed to increase bone mass. In this study in dogs, osteoclastic surfaces were clearly increased by the PTH infusion (11). Similarly, infusing $\mathrm{hPTH}(1-38)$ over a range of $3.2-100 \mu \mathrm{g} / \mathrm{kg} /$ day did not affect or cause bone loss hypercalcemia over the 14-day infusion period $(21,22)$. In most of these previous studies PTH has only been infused for periods of less than 2 weeks at doses high enough to cause hypercalcemia (6-9). The effects of prolonged (i.e. 6 weeks) infusions of low doses of PTH in ovariectomized rats, which do not induce hypercalcemia, have not been tested.

Our study has assessed the ability of prolonged low-dose infusion of $\left[\mathrm{Leu}^{27}\right]$-cyclo( $\left.\mathrm{Glu}^{22}-\mathrm{Lys}^{26}\right)$-hPTH$(1-31) \mathrm{NH}_{2}$ to increase cancellous bone volume in ovariectomized rats. The doses selected for this study were found to be below ( 0.05 and $0.1 \mathrm{nmole} / 100 \mathrm{~g} \mathrm{BW} /$ day) and slightly above $(0.5 \mathrm{nmole} / 100 \mathrm{~g} \mathrm{BW} /$ day $)$ the critical level which determines whether PTH will be anabolic or catabolic. The hypercalcemia caused by infusing $0.5 \mathrm{nmole} / 100 \mathrm{~g} \mathrm{BW} /$ day indicated the induction of resorption typical of hyperparathyroidism. Since infusing $0.1 \mathrm{nmole} / 100 \mathrm{~g}$ BW/day did not cause hypercalcemia, it approached the threshold for inducing resorption but according to measurements of cancellous bone volume, trabecular thickness and number it was not osteogenic.

It is not understood why the osteogenic activity of daily PTH on bone formation vanishes when the hormone is continuously infused, but there are several possibilities. Continuous infusions of PTH might (i) down regulate PTH receptors on mature osteoblasts (23); (ii) inhibit the production of osteogenic factors or stimulate the buildup of resorption-related signals (5); (iii) stimulate the expression of osteoclast differentiation factor on osteoblast/stromal cells to increase osteoclast differentiation and activation by progenitor cells (24); or (iv) stimulate the proliferation of M-CSF-responsive osteoclast progenitor cells in the bone marrow (25). It has also been reported that continuously infusing $0.01 \mu \mathrm{g}(0.106 \mathrm{nmole} / \mathrm{kg})$ or $0.1 \mu \mathrm{g}(1.06 \mathrm{nmole} / \mathrm{kg})$ recombinant human (rh) PTH(1-84)/100 g BW for 7 days into 12-week-old female rats reduced the number of cancellous bone osteoblasts and cancellous bone volume (26). But, surprisingly, infusing $5 \mu \mathrm{g}$ $(5.3 \mathrm{nmole} / \mathrm{kg})$ rhPTH$(1-84)$ dramatically increased the number of seemingly mature osteoblasts as expected which expressed osteocalcin, but it did not stain positively for insulin-like growth factor (IGF)-I or make bone. However, now they produced IGF binding protein (IGFBP)-3 and -4 which probably prevented them from staining positively for IGF-I and building bone by binding and inactivating IGF-I (26).

In summary, prolonged infusion of even low doses of PTH does not stimulate bone formation. This indicates that delivery by implanted pump would not be effective unless the device can be programmed to deliver the hormone or its analogs in bone-building boluses.

\section{References}

1 Dempster DW, Cosman F, Parisien M, Shen V \& Lindsay R. Anabolic actions of parathyroid hormone on bone. Endocrine Reviews 199314 690- 709.

2 Lindsay R, Nieves J, Formica C, Henneman E, Woelfert L, Shen V et al. Randomised controlled study of effect of parathyroid hormone on vertebral-bone mass and fracture incidence among post-menopausal women on oestrogen with osteoporosis. Lancet $1997350550-555$.

3 Morley P, Whitfield JF \& Willick GE. Anabolic effects of parathyroid hormone on bone. Trends in Endocrinology and Metabolism 19978 225-231.

4 Reeve J. PTH: a future role in the management of osteoporosis? Journal of Bone and Mineral Research 199611 440-445. 
5 Whitfield JF \& Morley P (Editors). Anabolic Treatments for Osteoporosis. Boca Raton: CRC Press, 1998.

6 Dobnig H \& Turner RT. The effects of programmed administration of human parathyroid hormone fragment (1-34) on bone histomorphometry and serum chemistry in rats. Endocrinology 1997138 4607-4612.

7 Tam CS, Heersche JNM, Murray TM \& Parsons JA. Parathyroid hormone stimulates the bone apposition rate independently of its resorptive action: differential effects of intermittent and continuous administration. Endocrinology 1982110 506-512.

8 Kitazawa R, Imai Y, Fukase M \& Ozawa H. Effects of continuous infusion of PTH and PTH-related peptide on rat bone in vivo: comparative study by histomorphometry. Bone and Mineral 1991 12 157-166.

9 Uzawa T, Hori M, Ejiri S \& Ozawa H. Comparison of the effects of intermittent and continuous administration of parathyroid hormone(1-34) on rat bone. Bone $199516477-484$.

10 Hock JM \& Gera I. Effects of continuous and intermittent administration and inhibition of resorption on the anabolic response of bone to parathyroid hormone. Journal of Bone and Mineral Research 19927 65-72.

11 Podbesek R, Edouard C \& Meunier PJ. Effects of two treatment regimes with synthetic human parathyroid hormone fragment on bone formation and the tissue balance of trabecular bone in greyhounds. Endocrinology 1983112 1000-1006.

12 Barbier J-R, Neugebauer W, Morley P, Ross V, Soska M, Whitfield JF et al. Bioactivities and secondary structures of constrained analogues of human parathyroid hormone: cyclic lactams of the receptor binding region. Journal of Medicinal Chemistry 199740 1373-1380.

13 Whitfield JF, Morley P, Willick G, Langille R, Ross V, MacLean S et al. Cyclization by a specific lactam increases the ability of human parathyroid hormone $(\mathrm{hPTH})-(1-31) \mathrm{NH}_{2}$ to stimulate bone growth in ovariectomized rats. Journal of Bone and Mineral Research 199712 1246-1252.

14 Rixon RH, Whitfield JF, Gagnon L, Isaacs RJ, MacLean S, Chakravarthy BR et al. Parathyroid hormone fragments may stimulate bone growth in ovariectomized rats by activating adenylyl cyclase. Journal of Bone and Mineral Research 19949 1179-1189.

15 Neugebauer W, Barbier J-R, Sung WL, Whitfield JF \& Willick GE Solution structure and adenylyl cyclase stimulating activities of C-terminal truncated human parathyroid hormone analogues. Biochemistry 199534 8835-8842.

16 Whitfield JF, Morley P, Willick GE, Ross V, Barbier J-R, Isaacs RJ et al. Stimulation of the growth of femoral trabecular bone in ovariectomized rats by the novel parathyroid hormone fragment, hPTH-(1-31) $\mathrm{NH}_{2}$ (Ostabolin). Calcified Tissue International 1996 $5881-87$.

17 Thompson DD, Simmons HA, Pirie CM \& Ze HZ. FDA guidelines and animal models for osteoporosis. Bone 199516 157-161.

18 Whitfield JF, Morley P, Ross V, Isaacs RJ \& Rixon RH. Restoration of severely depleted femoral trabecular bone in ovariectomized rats by parathyroid hormone-(1-34). Calcified Tissue International $199556227-231$.

19 Whitfield JF, Morley P, Ross V, Preston E, Soska M, Barbier J-R et al. The hypotensive actions of osteogenic and non-osteogenic parathyroid hormone fragments. Calcified Tissue International $199760302-308$.

20 Patton JS, Trinchero P \& Platz RM. Bioavailability of pulmonary delivered peptides and proteins: $\alpha$-interferon, calcitonins and parathyroid hormones. Journal of Controlled Release 199428 7985.

21 Gasser JA. Clinical and experimental results with PTH in the treatment of postmenopausal osteoporosis. In Bone Diseases and Osteoporosis, article 15. RG Russell (Chairman). London: IBC Technical Services Limited, 1994.

22 Gasser JA \& Jerome CP. Parathyroid hormone: a cure for osteoporosis? Triangle 199231 111-121.

23 Brown EM, Segre GV \& Goldring SR. Serpentine receptors for parathyroid hormone, calcitonin and extracellular calcium ions. Bailliere's Clinical Endocrinology and Metabolism $199610123-$ 161.

24 Tsukii K, Shima N, Mochizuki S, Yamaguchi K, Kinosaki M, Yano $\mathrm{K}$ et al. Osteoclast differentiation factor mediates an essential signal for bone resorption induced by $1 \alpha, 25$-dihydroxyvitamin $\mathrm{D}_{3}$, prostaglandin $\mathrm{E}_{2}$, or parathyroid hormone in the microenvironment of bone. Biochemical and Biophysical Research Communications 1998246 337-341.

25 Kanatani M, Sugimoto T, Takahashi Y, Kaji H, Kitazawa R \& Chihara K. Estrogen via the estrogen receptor blocks cAMPmediated parathyroid hormone (PTH)-stimulated osteoclast formation. Journal of Bone and Mineral Research 199813 854862.

26 Watson PH, Fraher LJ, Kiesel M, DeSousa D, Hendy G \& Hodsman AB. Enhanced osteoblast development after continuous infusion of rhPTH-(1-84) in the rat. Bone 199924 89-94.

Received 30 November 1998

Accepted 9 April 1999 